\title{
Sistem Pendukung Keputusan Seleksi Fasilitator Sumber Daya Manusia Menggunakan Metode Electre (Studi Kasus: Dinas Kesehatan Sibuhuan)
}

\author{
Nur Hasanah Daulay, Surya Darma Nasution, Fadlina* \\ Prodi Teknik Informatika, STMIK Budi Darma, Medan, Indonesia \\ Email: ${ }^{1}$ nurhasanahdaulay13@gmail.com, ${ }^{2}$ suryadarma@stmik-budidarma.ac.id, 3 ," fadlina@ stmik-budidarma.ac.id \\ Email Penulis Korespondensi: fadlina@stmik-budidarma.ac.id \\ Submitted 08-05-2020; Accepted 01-06-2020; Published 14-06-2020
}

\begin{abstract}
Abstrak
Selama ini dinas kesehatan melakukan seleksi fasilitator dengan cara diseleksi langsung oleh Kepala bagian Sumber Daya Manusia yaitu memberikan pertanyaan-pertanyaan terhadap fasilitator yang diseleksi mengenai kesehatan. Permasalahan yang dihadapi oleh dinas kesehatan dalam melakukan seleksi adalah sulit mempertimbangkan kriteria fasilitator dikarenakan kriteria yang berbeda-beda. Hal ini kurang efektif karena penilaian kriteria ini berpengaruh terhadap hasil seleksi yang diharapkan. Dalam menghadapi masalah seleksi fasilitator yang dilakukan oleh Kepala Sumber Daya Manusia dapat dibangun sistem pendukung keputusan dalam menghadapi masalah seleksi fasilitator yaitu dengan menggunakan metode ELECTRE. Kriteria yang akan dijadikan sebagai penilaian fasilitator seperti kemampuan, pengalaman, pendidikan, kreatif, dan kedisiplinan. Untuk itu Penulis mengharapkan agar aplikasi sistem pendukung keputusan seleksi fasilitator menerapkan metode ELECTRE ini dapat memudahkan inas kesehatan dalam seleksi fasilitator.
\end{abstract}

Kata Kunci: Sistem Pendukung Keputusan, Fasilitator, Dinas Kesehatan, ELECTRE.

\begin{abstract}
During this time the health department selected the facilitators by being selected directly by the Head of Human Resources, namely giving questions to the selected facilitators about health. The problem faced by the health department in conducting selection is that it is difficult to consider the facilitator's criteria due to different criteria. This is less effective because the evaluation of these criteria influences the expected selection results. In dealing with the problem of facilitator selection conducted by the Head of Human Resources, a decision support system can be built in dealing with the problem of selection of facilitators by using the ELECTRE method. Criteria that will be used as a facilitator's assessment such as ability, experience, education, creative, and discipline. For this reason, the author expects that the application of the facilitator selection decision support system to apply the ELECTRE method can facilitate health officials in the selection of facilitators.
\end{abstract}

Keywords: Decision Support System, Facilitator, Health Office, ELECTRE.

\section{PENDAHULUAN}

Semakin berkembangnya ilmu teknologi rekayasa perangkat lunak yang berubah dari waktu ke waktu memunculkan ide-ide dan gagasan perkembangan yang dilakukan manusia setiap harinya. Pada era perkambangan zaman seperti ini sangat banyak sekali ilmu teknologi rekayasa perangkat lunak yang dapat dijadikan sebagai sarana komunikasi pengganti manusia yang dimasukkan dalam komputerisasi. Tidak menutup kemungkinan pada era sekarang sudah banyak kita temui ide manusia yang dimasukkan kedalam intiruksi sebagai perintah komputer dalam menjalankan tugasnya. Semakin banyaknya tercipta ide manusia yang dituangkan kedalam komputer maka tidak menutup kemungkinan banyak kekurangan dan kelebihan yang ditimbulkan oleh komputer yang telah diprogram tersebut

Fasilitator adalah orang yang diseleksi oleh dinas kesehatan untuk membantu dalam peningkatan kesehatan ditengahtengah masyarakat luas[1]. Semakin seorang fasilitator mempunyai bekal ilmu yang dilatih oleh dinas kesehatan maka semakin baik pemahaman dan tingkat kesehatan masyarakat. Sumber daya manusia yang merupakan seseorang yang mempunyai kemampuan untuk menjadi manusia seutuhnya,dimana dapat berguna bagi dirinya maupun bagi orang lain disekitarnya.

Selama ini Dinas Kesehatan melakukan seleksi fasilitator dengan cara diseleksi langsung oleh Kepala bagian Sumber Daya Manusia yaitu memberikan pertanyaan-pertanyaan terhadap fasilitator yang diseleksi mengenai kesehatan. Permasalahan yang dihadapi oleh dinas kesehatan dalam melakukan seleksi adalah sulit mempertimbangkan kriteria fasilitator dikarenakan kriteria yang berbeda-beda. Hal ini kurang efektif karena penilaian kriteria ini berpengaruh terhadap hasil seleksi yang diharapkan.Adapun kriteria yang dipergunakan dalam seleksi fasilitator seperti kemampuan, pengalaman, pendidikan, kreatif, dan kedisiplinan. Dalam menangani permasalahan yang terjadi dibutuhkan suatu sistem komputerisasi yang dapat membantu dinas kesehatan dalam melakukan seleksi fasilitator dengan memasukkan kriteria-kriteria yang ada sebelumnya kedalam suatu sistem pendukung keputusan.

\section{METODE PENELITIAN}

\subsection{Sistem Pendukung Keputusan}

Sistem Pendukung Keputusan / Decision Support System (DSS) merupakan suatu sistem atau informasi yang menyediakan informasi, pemodelan dan pemanipulasian data untuk melakukan suatu proses pengambilan keputusan yang dilakukan oleh pelaku bisnis untuk pengambilan keputusan dalam situasi yang semi terstruktur dan situasi yang tidak terstruktur sehingga dapat memudahkan pihak-pihak yang ingin mengambil suatu keputusan dengan mudah dan akurat[2]-[5]. 


\subsection{Metode Elimination And Choice Translation Reality (ELECTRE)}

Menurut Janko dan Bernoider, Electre merupakan salah satu metode pengambilan keputusan multikriteria berdasarkan pada konsep Outranking dengan menggunakan perbandingan berpasangan dari alternatif-alternatif berdasarkan setiap kriteria yang sesuai. Metode Electre digunakan pada kondisi dimana alternatif yang kurang sesuai dengan kriteria dieliminasi, dan alternatif yang sesuai dapat dihasilkan[6]-[9].

Dengan kata lain, Electre digunakan untuk kasus-kasus dengan banyak alternatif namun hanya sedikit kriteria yang dilibatkan. Suatu alternatif dikatakan mendominasi alternatif yang lainnya jika satu atau lebih kriterianya melebihi (dibandingkan dengan kriteria dari alternatif yang lain) dan sama dengan kriteria lain yang tersisa.

Langkah-langkah yang dilakukan dalam penyelesaian masalah menggunakan metode Electre [10]-[13] sebagai berikut:

1. Membentuk perbandingan berpasangan setiap alternatif pada setiap kriteria dan dinormalisasikan ke dalam suatu skala yang dapat dibandingkan.

$r_{i j}=\frac{x_{i j}}{\sqrt{\sum_{i=1}^{m} x_{i j}^{2}}}$ untuk $i=1,2,3, \ldots$, m dan $j=1,2,3, \ldots, n$.

2. Memberikan bobot pada setiap kriteria yang mengekspresikan kepentingan relatifnya $\left(\mathrm{w}_{\mathrm{i}}\right)$ dengan cara setiap kolom dari matriks X dikalikan dengan bobot-bobot yang ditentukan oleh pembuat keputusan

3. Menentukan himpunan dari concordance dan discordance

Untuk setiap pasang dari alternatif $k$ dan $l(k . l=1,2,3, \ldots, \mathrm{m}$ dan $k \neq l)$ kumpulan kriteria $\mathrm{j}$ dibagi menjadi dua himpunan bagian, yaitu concordance dan discordance. Sebuah kriteria dalam suatu alternatif termasuk concordance jika :

$C_{k l}=\left\{j, v_{k j} \geq v_{l j}\right\}$, untuk $j=1,2,3, \ldots, n$

Sebaliknya, komplementer dari himpunan bagian ini adalah discordance, yaitu bila

$D_{k l}=\left\{j, v_{k j}<v_{l j}\right\}$, untuk $j=1,2,3, \ldots, n$

4. Menentukan matriks concordance dan discordance

Untuk menetukan nilai dari elemen-elemen pada matriks concordance adalah dengan menjumlahkan bobot- bobot yang termasuk dalam himpunan bagian concordance, secara matematisnya adalah sebagai berikut:

$C_{k l}=\sum_{\mathrm{j} \in C_{\mathrm{kl}}} \mathrm{wj}$

Untuk menetukan nilai dari elemen-elemen pada matriks discordance adalah dengan membagi maksimum selisih nilai kriteria yang termasuk dalam himpunan bagian discordance dengan maksimum selisih nilai seluruh kriteria yang ada, secara matematisnya adalah sebagai berikut :

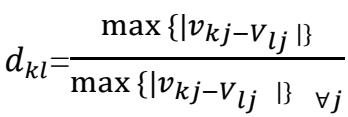

5. Menetukan matriks dominan concordance dan discordance

Dominasi matriks concordance dibangun dengan menggunakan nilai threshold untuk indeks concordance, yaitu dengan membandingkan setiap nilai elemen matriks concordance dengan nilai threshold. Sebagai contoh, $\mathrm{A}_{\mathrm{k}}$ hanya akan memiliki kesempatan untuk mendominasi $\mathrm{A}_{l}$ jika indeks concordance $C_{k l}$ yang sesuai melebihi setidaknya pada nilai threshold tertentu yaitu c.

$\mathrm{C}_{\mathrm{kl}} \geq \underline{\mathrm{c}}$

Nilai threshold dapat ditentukan sebagai rata-rata indeks concordance, dengan nilai threshold $\underline{\mathrm{c}}$ _adalah:

$\underline{\mathrm{C}}=\frac{\sum_{k=1}^{m} \sum_{l=1}^{m} C_{k l}}{m(m-1)}$

Berdasarkan nilai threshold, nilai setiap elemen matriks F sebagai matriks dominan concordance ditentukan sebagai berikut:

$f_{k l}=\left\{\begin{array}{c}1, j i k a c_{k l} \geq \underline{c} \\ 0, j i k a c_{k l<} \underline{c}\end{array}\right.$

Demikian pula, dominasi matriks discordance $G$ didefinisikan dengan menggunakan nilai threshold $\underline{\mathrm{d}}$, dimana $\underline{\mathrm{d}}$ didefinisikan sebagai berikut:

$\underline{d}=\frac{\sum_{k=1}^{m} \sum_{l=1}^{m} d_{k l}}{m(m-1)}$

Di mana nilai setiap elemen untuk matriks $\mathrm{G}$ sebagai matriks dominan discordance ditentukan sebagai berikut:

$g_{k l}=\left\{\begin{array}{l}1, j i k a \quad c_{k l} \geq \underline{d} \\ 0, j i k a \quad c_{k l}<\underline{d}\end{array}\right.$ 
6. Menentukan matriks dominan agregat (matriks E), dengan rumus :

$$
e_{k l}=f_{k l} \times g_{k l}
$$

7. Mengeliminasi alternatif

Matriks E memberikan urutan pilihan di setiap alternatif, yaitu bila $e_{k l}=1$ maka alternatif $A_{k}$ merupakan pilihan yang lebih baik daripada $A_{1}$. Sehingga baris dalam matriks $E$ yang memiliki jumlah $e_{k 1}=1$ paling sedikit dapat dieliminasi, dengan demikian alternatif terbaik adalah yang mendominasi alternatif lainnya.

\section{HASIL DAN PEMBAHASAN}

Dalam proses metode ELECTRE, diperlukan dalam penentuan kriteria yang akan dijadikan bahan perhitungan dan pertimbangan pada proses seleksi fasilitator. Hal tersebut dimaksud untuk menentukan siapa yang akan terpilih sebagai fasilitator. Adapun kriteria-kriteria yang menjadi bahan perhitungan dan pertimbangan dapat dilihat pada tabel berikut :

Tabel 1. Keterangan Kriteria

\begin{tabular}{|c|c|}
\hline Kriteria & Keterangan \\
\hline kemamnuan & Kemampuan merupakan skil yang ditunjukan fasilitator $\quad$ dalam seleksi baik $\quad$ dalam \\
\hline кemampuan & komunikasi dan membantu peserta dalam memberikan pertanyaan terhadap narumber. \\
\hline pengalaman & Pengalaman merupakan kegiatan kerja yang pernah dilalui oleh fasilitator \\
\hline pendidikan & Pendidikan merupakan proses belajar yang ditempuh oleh seorang fasilitator \\
\hline kreatif & $\begin{array}{l}\text { Kreatif merupakan tindakan yang muncul untuk menyelesaikan suatu permasalahan sehingga } \\
\text { teratasi dengan baik oleh fasilitator. }\end{array}$ \\
\hline kedisiplinan & $\begin{array}{l}\text { Kedisiplinan adalah kemampuan tepat waktu dan manajemen pengaturan waktu yang sesuai } \\
\text { dengan waktu yang telah ditetapkan. }\end{array}$ \\
\hline
\end{tabular}

Dalam Proses metode ELECTRE, diperlukan dalam penentuan kriteria dan bobot yang akan dijadikan bahan perhitungan dan pertimbangan. Berdasarkan langkah-angkah menggunakan metode fuzzy Multiple (FMADM) maka yang harus dilakukan dalam proses seleksi fasilitator adalah sebagai berikut:

Memberikan nilai setiap alternatif (Ai) dan setiap kriteria $(\mathrm{Cj})$ yang sudah ditentukan:

1. Rating kecocokan dari setiap alternatif pada setiap kriteria

Tabel 2. Sampel Data Sebelum dihitung

\begin{tabular}{cccccc}
\hline \multirow{2}{*}{ Alternatif } & \multicolumn{5}{c}{ Kiteria } \\
\cline { 2 - 6 } & $\mathrm{C} 1$ & $\mathrm{C} 2$ & $\mathrm{C} 3$ & $\mathrm{C} 4$ & $\mathrm{C5}$ \\
\hline Ahmad Fauzi & 81 & 80 & 70 & 82 & 83 \\
Indah Aminih & 55 & 70 & 80 & 72 & 62 \\
Ilmah Wahda Dly & 93 & 80 & 60 & 93 & 83 \\
Misbah Agustina Hsb & 76 & 80 & 80 & 63 & 85 \\
Amiyanti Hsb & 82 & 90 & 80 & 73 & 63 \\
\hline
\end{tabular}

2. Nilai Rata-rata pada setiap kriteria

Berdasarkan identifikasi masalah yang dilakukan maka perlu diidentifikasi serangkaian kriteria penilaian.

Tabel 3. Kriteria

\begin{tabular}{cc}
\hline Kriteria & Keterangan \\
C1 & Kemampuan \\
C2 & Pendidikan \\
C3 & Pengalaman \\
C4 & kreatif \\
C5 & Kedisiplinan \\
\hline
\end{tabular}

Dengan bobot yang dimiliki dari masing-masing kriteria adalah sebagai berikut :

$\mathrm{W}=(5,4,4,2,3)$

Tabel 4. Sampel Data

\begin{tabular}{lllllll}
\hline \multirow{2}{*}{ Nik } & \multirow{2}{*}{ Nama Fasilitator } & \multicolumn{5}{c}{ Kriteria } \\
\cline { 3 - 7 } & & C1 & C2 & C3 & C4 & C5 \\
\hline K001 & Ahmad Fauzi & 4 & 3 & 5 & 4 & 4 \\
K002 & Indah Aminih & 1 & 5 & 3 & 3 & 2 \\
K003 & Ilma Wahda Dly & 5 & 5 & 4 & 5 & 4 \\
K004 & Misbah Agustina & 3 & 2 & 4 & 2 & 4 \\
K005 & Almiyanti Hsb & 4 & 1 & 2 & 3 & 2 \\
\hline
\end{tabular}


Untuk menyesaikan permasalahan tersebut dengan menggunakan metode Electre dengan langkah-langkah sebagai

1. Melakukan normalisasi matriks keputusan.

Dalam prosedur ini, setiap atribut di ubah menjadi nilai yang comparable.

Setiap normalisasi dari nilai Xij dapat dilakukan dengan rumus :

$r_{i j}=\frac{x_{i j}}{\sqrt{\sum_{i=1}^{m} x_{i j}^{2}}}$ untuk $i=1,2,3, \ldots$, m dan $j=1,2,3, \ldots, n$.

Normalisasi pada kriteria $\mathrm{C} 1$

$$
\begin{aligned}
\left|X_{1}\right| & =\sqrt{4^{2} 1^{2} 5^{2} 3^{2} 4^{2}} \\
= & 16+1+25+9+16 \\
& =\sqrt{67} \\
& =8,1853 \\
r_{11} & =\frac{x 11}{x 1}=\frac{4}{8,1853}=0,4886 \\
r_{21} & =\frac{x 21}{x 1}=\frac{1}{8,1853}=0,1221 \\
r_{31} & =\frac{x 31}{x 1}=\frac{5}{8,1853}=0,6108 \\
r_{41} & =\frac{x 41}{x 1}=\frac{3}{8,1853}=0,3665 \\
r_{51} & =\frac{x 51}{x 1}=\frac{4}{8,1853}=0,4886
\end{aligned}
$$

Dari perhitungan diatas diperoleh matriks sebagai berikut :

$$
R=\left[\begin{array}{lllll}
0,4886 & 0,3750 & 0,5976 & 0,5039 & 0,5345 \\
0,1221 & 0,6250 & 0,3585 & 0,3779 & 0,2672 \\
0,6108 & 0,6250 & 0,4780 & 0,6299 & 0,5345 \\
0,3665 & 0,2500 & 0,4780 & 0,2519 & 0,5345 \\
0,4886 & 0,1250 & 0,2390 & 0,3779 & 0,2672
\end{array}\right]
$$

2. Melakukan pembobotan pada matriks yang telah dinormalisasi.

Setelah dinormalisasi, setiap kolom dari matriks $\mathrm{R}$ dikalikan dengan bobot-bobot $\left(w_{j}\right)$ yang ditentukan oleh pembuat keputusan. Sehingga,weighted normalized matriks adalah $\mathrm{V}=\mathrm{RW}$ yang ditulis dalam rumus : $V=R$. $W$

$$
\begin{aligned}
& \mathrm{V}=\left[\begin{array}{cccc}
v_{11} & v_{12} & \ldots & v_{1 n} \\
v_{21} & v_{22} & \ldots & v_{2 n} \\
\ldots & \ldots & \ldots & \ldots \\
v_{m 1} & v_{m 2} & \ldots & v_{m n}
\end{array}\right] \mathrm{RW}=\left[\begin{array}{llll}
w_{1} r_{11} & W_{2} r_{12} & \ldots & w_{n} r_{1 n} \\
w_{1} r_{21} & W_{2} r_{22} & \ldots & w_{n} r_{2 n} \\
\ldots & \ldots & \ldots & \ldots \\
w_{1} r_{m 1} & W_{2} r_{m 2} & \ldots & w_{n} r_{m n}
\end{array}\right] \\
& v_{11}=w_{1} r_{11}=(5)(0,4886)=2,4433 \\
& v_{21}=w_{1} r_{21}=(5)(0,1221)=0,6108 \\
& v_{31}=w_{1} r_{31}=(5)(0,6108)=3,0542
\end{aligned}
$$

Dari perhitungan diatas diperoleh matriks sebagai berikut :

$$
\mathrm{V}=\left[\begin{array}{lllll}
2,4433 & 1,5000 & 2,3904 & 1,0079 & 1,6035 \\
0,6108 & 2,5000 & 1,4342 & 0,7559 & 0,8017 \\
3,0542 & 2,5000 & 1,9123 & 1,2598 & 1,6035 \\
1,8325 & 1,0000 & 1,9123 & 0,5039 & 1,6035 \\
2,4433 & 0,5000 & 0,9561 & 0,7559 & 0,8017
\end{array}\right]
$$

3. Menentukan himpunan concordance dan discordance index. Untuk setiap pasang dari alternatif $\mathrm{k}$ dan $l(\mathrm{k}, l=1,2,3, \ldots, \mathrm{m}$ dan $\mathrm{k} \neq l)$ kumpulan $\mathrm{J}$ kriteria dibagi menjadi dua himpunan bagian yaitu concordance dan discordance. Sebuah kriteria dalam suatu alternatif termasuk concordance jika:

$C_{k l}=\left\{j, v_{k j} \geq v_{l j}\right\}$, untuk $j=1,2,3, \ldots, n$

Sebaliknya, komplementer dari himpunan bagian concordance adalah himpunan discordance, yaitu bila:

$D_{k l}=\left\{j, v_{k j}<v_{l j}\right\}$, untuk $j=1,2,3, \ldots, n$

a. Concocrdance

Sebuah kriteria dalam suatu alternatif termasuk cordance.

Himpunan concordance index dihitung berdasarkan :

$$
\begin{aligned}
C_{k l}= & \left\{j, v_{k j} \geq v_{i j}\right\}, \text { untuk } j=1,2,3, \ldots, n \\
\mathrm{~K}=1 \quad & \mathrm{i}=1 \mathrm{C}_{11} \text { identitas }=\{\} \\
& \mathrm{i}=2 \mathrm{C}_{12} \\
& \mathrm{j}=1 \text { jika } v_{11} \geq v_{21}=2,4433 \geq 0,6108 \text { ya } \\
& \mathrm{j}=2 \text { jika } v_{12} \geq v_{22}=1,5000 \geq 2,5000 \text { tidak } \\
& \mathrm{j}=3 \text { jika } v_{13} \geq v_{23}=2,3904 \geq 1,4342 \text { ya }
\end{aligned}
$$


$\mathrm{j}=4$ jika $v_{14} \geq v_{24}=1,0079 \geq 0,7559$ ya
$\mathrm{j}=5$ jika $v_{15} \geq v_{25}=1,6035 \geq 0,8017$ ya
$=\{1,3,4,5\}$

Tabel 5. Concordance

\begin{tabular}{ll}
\hline $\mathrm{C}_{\mathrm{k} 1}$ & Himpunan \\
\hline $\mathrm{C} 12$ & $1,3,4,5$ \\
$\mathrm{C} 13$ & 3,5 \\
$\mathrm{C} 14$ & $1,2,3,4,5$ \\
$\mathrm{C} 15$ & $1,2,3,4,5$ \\
$\mathrm{C} 21$ & 2 \\
$\mathrm{C} 23$ & 2 \\
$\mathrm{C} 24$ & 2,4 \\
$\mathrm{C} 25$ & $2,3,4,5$ \\
$\mathrm{C} 31$ & $1,2,4$ \\
$\mathrm{C} 32$ & $1,2,4,5$ \\
$\mathrm{C} 34$ & $1,2,3,4$ \\
$\mathrm{C} 35$ & $1,2,3,4,5$ \\
$\mathrm{C} 41$ & 5 \\
$\mathrm{C} 42$ & $1,3,5$ \\
$\mathrm{C} 43$ & 3,5 \\
$\mathrm{C} 45$ & $2,3,5$ \\
$\mathrm{C} 51$ & 1 \\
$\mathrm{C} 52$ & $1,4,5$ \\
$\mathrm{C} 53$ & 0 \\
$\mathrm{C} 54$ & 1,4 \\
\hline
\end{tabular}

b. Discordance

Komplementer dari subset ini adalah :

$C_{k l}=\left\{j, v_{k j}<v_{i j}\right\}$, untuk $j=1,2,3, \ldots, n$

$\mathrm{D}=1 \quad \mathrm{i}=1 \mathrm{D}_{11}$ identitas $=\{\}$

$\mathrm{i}=2 \mathrm{D}_{12}$

$\mathrm{j}=1$ jika $v_{11}<v_{21}=2,4433<0,6108$ tidak

$\mathrm{j}=2$ jika $v_{12}<v_{22}=1,5000<2,5000$ ya

$\mathrm{j}=3$ jika $v_{13}<v_{23}=2,3904<1,4342$ tidak

$\mathrm{j}=4$ jika $v_{14}<v_{24}=1,0079<0,7559$ tidak

$\mathrm{j}=5$ jika $v_{15}<v_{25}=1,6035<0,8017$ tidak $=\{2\}$

Tabel 6. Discordance

\begin{tabular}{ll}
\hline$D_{\mathrm{k1}}$ & Himpunan \\
\hline D12 & 2 \\
D13 & $1,2,4$ \\
D14 & 0 \\
D15 & 0 \\
D21 & $1,3,4,5$ \\
D23 & $3,4,5$ \\
D24 & 1,3 \\
D25 & 0 \\
D31 & 3,5 \\
D32 & 0 \\
D34 & 4,5 \\
D35 & 0 \\
D41 & 1.2 .3 .4 \\
D42 & 3,4 \\
D43 & $1,2,4$ \\
D45 & 1,4 \\
D51 & $2,3,4,5$ \\
D52 & 2,3 \\
D53 & $1,2,3,4,5$ \\
D54 & $2,3,5$ \\
\hline
\end{tabular}


4. Menentukan matriks concordance dan discordance

a. Concordance

Untuk menentukan nilai dari elemen-elemen pada matriks concordance adalah menjumlahkan bobot-bobot yang termasuk dalam subset discordance, secara matematisnya.

$$
\begin{aligned}
C_{k l} & =\sum_{\mathrm{j} \in \mathrm{C}_{\mathrm{kl}}} \mathrm{wj} \\
\mathrm{C}_{12} & =\mathrm{W}_{1}+\mathrm{W}_{3}+\mathrm{W}_{4}+\mathrm{W}_{5} \\
& =5+4+2+3=14 \\
\mathrm{C}= & {\left[\begin{array}{ccccc}
- & 14 & 7 & 18 & 18 \\
4 & - & 4 & 6 & 13 \\
11 & 14 & - & 15 & 18 \\
3 & 12 & 7 & - & 11 \\
5 & 10 & 0 & 7 & -
\end{array}\right] }
\end{aligned}
$$

b. Discordance

untuk menentukan nilai dari elemen-elemen pada matrisk discordance dengan maksimum selisih nilai kriteria yang termasuk kedalam himpunan discordance dengan maksimum selisih nilai seluruh kriteria yang ada, secara matimatisnya:

$$
\begin{gathered}
\quad d_{k l}=\frac{\max \left\{\mid v_{\left.k j-V_{l j} \mid\right\}}\right.}{\max \left\{\mid v_{\left.k j-V_{l j} \mid\right\} \quad \forall j}\right.} \\
\mathrm{D}_{12}=\frac{\max \{([1,5000-2,5000])\}}{\max \{([2,4433-0,6108] ;[1,5000-2,5000] ;[2,3904-1,4342] ;[1,0079-0,7559] ;[1,6035-0,8017])\}} \\
\quad=\frac{\{([1])\}}{\max \{([1,8325] ;[1] ;[0,9562] ;[0,2520] ;[0,8018])\}}=\frac{1}{1,8325}=0,5457 \\
{\left[\begin{array}{ccccc}
- & 0,5457 & 0,6109 & 0 & 0 \\
1 & - & 0,3913 & 0,2783 & 0 \\
0,4781 & 0 & - & 0,5345 & 0 \\
1 & 0,3187 & 1 & - & 0,4072 \\
1 & 1 & 1 & 1 & -
\end{array}\right]}
\end{gathered}
$$

5. Menentukan matrisk domonan corcodance dan discordsnce

a. Menghitung matrik dominan concordance. Matrik F sebagai matrik dominan concordance dapat dibangun dengan bantuan nilai threshold, yaitu dengan membandingkan setiap nilai elemen matriks concordance dengan nilai threshold.

$C_{k l} \geq \underline{\mathrm{c}}$

Dengan nilai threshold $(\subset)$ adalah:

$\underline{\mathrm{C}}=\frac{\sum_{k=1}^{m} \sum_{l=1}^{m} C_{k l}}{m(m-1)}$

$\underline{\mathrm{C}}=\frac{14+7+18+18+4+4+6+13+11+14+15+18+3+12+7+11+5+10+7}{\mathbf{5 ( 5 - 1 )}}$

$\underline{\mathrm{C}}=\frac{197}{20}=9,85$

elemen matriks $\mathrm{F}$ ditentukan sebagai berikut:

$f_{k l}=\left\{\begin{array}{c}1, j i k a c_{k l} \geq \underline{c} \\ 0, j i k a c_{k l}<\underline{c}\end{array}\right.$

Sehingga elemen matriks F sebagai berikut

$\mathrm{F}=\left[\begin{array}{ccccc}- & 1 & 0 & 1 & 1 \\ 0 & - & 0 & 0 & 1 \\ 1 & 1 & - & 1 & 1 \\ 0 & 1 & 0 & - & 1 \\ 0 & 1 & 0 & 0 & -\end{array}\right]$

b. Menghitung matriks dominan discordance

Matriks G sebagai matriks dominan discordance dapat dibangun dengan bantuan nilai 395hreshold:

$\underline{d}=\frac{\sum_{k=1}^{m} \sum_{l=1}^{m} d_{k l}}{m(m-1)}$

$\underline{\mathrm{D}}=\frac{0,5457+0,6109+0+0+1+0,3913+0,2783+0+0,4781+0+0,5343+0+1+0,3187+1+0,4072+1+1+1+1}{5(5-1)}$

$\underline{\mathrm{D}}=\frac{10,5645}{20}=0,5282$

Elemen matriks $\mathrm{G}$ ditentukan dengan :

$g_{k l}=\left\{\begin{array}{l}1, j i k a c_{k l} \geq \underline{d} \\ 0, j i k a c_{k l}<\underline{d}\end{array}\right.$

Sehingga Elemen matriks $\mathrm{G}$ sebagai berikut 


$$
G=\left[\begin{array}{ccccc}
- & 1 & 0 & 0 & 0 \\
1 & - & 0 & 0 & 0 \\
0 & 0 & - & 1 & 0 \\
1 & 0 & 1 & - & 0 \\
1 & 1 & 1 & 1 & -
\end{array}\right]
$$

6. Menentukan aggregate dominance matriks

Matriks E sebagai aggregate dominance matriks adalah matriks yang setiap elemennya merupakan perkalian antara elemen matriks F dengan elemen matriks $\mathrm{G}$ yang bersesuaian, secara matematis dapat dinyatakan sebagai:

$e_{k l}=f_{k l} \times g_{k l}$

$$
F=\left[\begin{array}{ccccc}
- & 1 & 0 & 1 & 1 \\
0 & - & 0 & 0 & 1 \\
1 & 1 & - & 1 & 1 \\
0 & 1 & 0 & - & 1 \\
0 & 1 & 0 & 0 & -
\end{array}\right] * G=\left[\begin{array}{ccccc}
- & 1 & 0 & 0 & 0 \\
1 & - & 0 & 0 & 0 \\
0 & 0 & - & 1 & 0 \\
1 & 0 & 1 & - & 0 \\
1 & 1 & 1 & 1 & -
\end{array}\right]
$$

$\mathrm{E}=\left[\begin{array}{ccccc}- & 1 & 0 & 0 & 0 \\ 1 & - & 0 & 0 & 0 \\ 0 & 0 & - & 1 & 0 \\ 0 & 1 & 0 & - & 0 \\ 0 & 1 & 0 & 0 & -\end{array}\right]$

7. Melakukan Eliminasi alternatif yang less favourable.

Matriks E memberikan urutan pilihan dari setiap alternatif bila $e_{k l}=1$ maka alternative $A_{k}$ merupakan pilihan yang lebih baik dari pada $A_{l}$. Sehingga baris dalam matriks E yang memiliki jumlah $e_{k l}=1$ paling sedikit dapat di eliminasi. Dengan demikian alternatif terbaik adalah yang mendominasi alternatif lainnya. Pada matriks E, ada baris ke-1, baris ke-2, baris ke-3 baris ke-4 dan baris ke-5 yang memiliki elemen $e_{k l}=1$, tetapi apa bila matriks E saling mendominasi, maka perbandingan untuk mencari yang terbaik dilakukan dengan mengambil perbandingan pada matriks $\mathrm{V}$ (weghteh normalized matrik). Jadi alternatif terbaik adalah terdapat pada $A_{3}$ dengan NIK : 003 atas nama Ilmah Wahda Dly.

\section{KESIMPULAN}

Berdasarkan uraian pembahasan dari penelitian yang telah dilakukan, maka dapat diperoleh kesimpulan sebagai berikut:

1. Prosedur seleksi fasilitator pada kantor dinas kesehatan sibuhuan diseleksi langsung oleh Kepala bagian Sumber Daya Manusia yaitu memberikan pertanyaan-pertanyaan terhadap fasilitator yang diseleksi mengenai kesehatan. Kemudian kriteria-kriteria yang digunakan dalam seleksi seperti kemampuan, pengalaman, pendidikan, kreatif, dan kedisiplinan.

2. Penerapan metode Electre ini dilakukan dengan perbandingan kriteria dan sub kriteria terhadap masing-masing kriteria, kemudian menghitung normalisasi kriteria, dan untuk selanjutnya menghitung hasil perangkingan dari seluruh kriteria.

3. Perancangan sistem pendukung keputusan seleksi fasilitator menerapkan aplikasi Microsoft Visual Studio 2008 dan database yang digunakan adalah MySQL, untuk alat bantu yang digunakan adalah UML yaitu berupa use case diagram, activity diagram..

\section{REFERENCES}

[1] F. Dan and P. Kapasitas, "Penjelasan ii fasilitasi dan pengembangan kapasitas 2.1.," pp. 1-81.

[2] D. Nofriansyah, Konsep Data Mining Vs Sistem Pendukung Keputusan. 2015.

[3] T. Limbong et al., Sistem Pendukung Keputusan: Metode \& Implementasi. Medan: Yayasan Kita Menulis, 2020.

[4] S. Kusumadewi, S. Hartati, A. Harjoko, and Retantyo Wardoyo, Fuzzy Multi-Attribute Decision Making (FUZZY MADM). 2006.

[5] Kusrini, Konsep dan Aplikasi Sistem Pendukung Keputusan. 2007.

[6] L. N. Zulita, "Penerapan Metode ELECTRE Dalam Pengambilan Keputusan Pemilihan Produk Unggulan Daerah," J. Inf. Sist. Res., vol. 1, no. 3, pp. 162-167, 2020.

[7] M. Mesran, R. Rusiana, and M. Sianturi, "Decision Support System for Termination of Employment using Elimination and Choice Translation Reality Method," J. Teknol. dan Sist. Komput., vol. 6, no. 4, p. 135, 2018.

[8] J. S. Vera Delmayanti, Yuhandri, "Implementasi Metode Elimination Et ChoixTraduisant La Realite (ELECTRE) dalam Penentuan Pegawai Berprestasi,” J. Inf. Teknol., vol. 1, no. 3, pp. 33-39, 2019.

[9] Mesran, Pristiwanto, and D. Sihombing, "IMPLEMENTASI METODE ELECTRE DALAM MENENTUKAN RICE COOKER TERBAIK," J. Telemat., vol. 11, no. 2, pp. 43-54, 2018.

[10] M. Mesran, A. Rizki, and N. Silalahi, "Application of Multi Criteria Supporting Elemination and Choice Translation Reality (ELECTRE) Decision in Determining Scholarship Recipients for Employee Children at PT. Nusira," IJICS (International J. Informatics Comput. Sci., vol. 3, no. 1, pp. 15-23, 2019.

[11] S. Sundari, A. Wanto, S. Saifullah, and I. Gunawan, "Sistem Pendukung Keputusan Dengan Menggunakan Metode Electre Dalam Merekomendasikan Dosen Berprestasi Bidang Ilmu Komputer (Study Kasus di AMIK \& STIKOM Tunas Bangsa)," in Conference Paper, 2017, no. September.

[12] S. R. Ningsih, I. S. Damanik, I. Gunawan, and W. Saputra, "SISTEM PENDUKUNG KEPUTUSAN DENGAN MENGGUNAKAN METODE ELECTRE DALAM MENENTUKAN PENERIMA PROGRAM INDONESIA PINTAR (PIP) MELALUI KARTU INDONESIA PINTAR (KIP) (STUDI KASUS: SD SWASTA AL - WASHLIYAH MOHO KABUPATEN SIMALUNGUN)," 
JURIKOM (Jurnal Riset Komputer), Vol. 7 No. 3, Juni 2020 e-ISSN 2715-7393 (Media Online), p-ISSN 2407-389X (Media Cetak)

DOI 10.30865/jurikom.v7i3.2172

Hal 390-397

KOMIK (Konferensi Nas. Teknol. Inf. dan Komputer), vol. 1, no. 1, Nov. 2017.

[13] W. Fauzi, "Sistem Pendukung Keputusan Penerima Bantuan Dana Ratilahu Dengan Menggunakan Metode Electre," Semin. Nas. Teknol. Inf. dan Komun., pp. 1-8, 2016. 